\title{
The Zebrafish nrc Mutant Reveals a Role for the Polyphosphoinositide Phosphatase Synaptojanin 1 in Cone Photoreceptor Ribbon Anchoring
}

\author{
Heather A. Van Epps, ${ }^{1}$ Mitsuko Hayashi, ${ }^{2}$ Louise Lucast, ${ }^{2}$ George W. Stearns, ${ }^{1}$ James B. Hurley, ${ }^{1}$ Pietro De Camilli, ${ }^{2}$ and \\ Susan E. Brockerhoff ${ }^{1}$ \\ ${ }^{1}$ Department of Biochemistry, University of Washington School of Medicine, Seattle, Washington 98195, and 2Department of Cell Biology and Howard \\ Hughes Medical Institute, Boyer Center for Molecular Medicine, Yale University School of Medicine, New Haven, Connecticut 06510
}

\begin{abstract}
Visual, vestibular, and auditory neurons rely on ribbon synapses for rapid continuous release and recycling of synaptic vesicles. Molecular mechanisms responsible for the properties of ribbon synapses are mostly unknown. The zebrafish vision mutant $n r c$ has unanchored ribbons and abnormal synaptic transmission at cone photoreceptor synapses. We used positional cloning to identify the nrc mutation as a premature stop codon in the synaptojanin1 (synj1) gene. Synaptojanin 1 (Synj1) is undetectable in $n r c$ extracts, and biochemical activities associated with it are reduced. Furthermore, morpholinos directed against synj1 phenocopy the $n r c$ mutation. Synj1 is a polyphosphoinositide phosphatase important at conventional synapses for clathrin-mediated endocytosis and actin cytoskeletal rearrangement. In the $n r c$ cone photoreceptor pedicle, not only are ribbons unanchored, but synaptic vesicles are reduced in number, abnormally distributed, and interspersed within a dense cytoskeletal matrix. Our findings reveal a new role for Synj1 and link phosphoinositide metabolism to ribbon architecture and function at the cone photoreceptor synapse.
\end{abstract}

Key words: ribbon synapse; synaptojanin; retina; cone photoreceptor; zebrafish; sensory neurons

\section{Introduction}

Sensory cells of the auditory, vestibular, and visual systems rely on ribbon synapses to transmit sensory information to afferent neurons. The ribbon, the most conspicuous structural specialization of these synapses, appears to be a platform that tethers and coordinates exocytosis of synaptic vesicles. Compared with conventional synaptic terminals, ribbon synaptic terminals can release vesicles continuously at exceptionally rapid rates, up to several thousand per second, and have an inordinately large pool of vesicles (Parsons et al., 1994; Rieke and Schwartz, 1996; von Gersdorff et al., 1996). With such high rates of continuous exocytosis, ribbon synapses also have mechanisms for efficient endocytosis and recycling of vesicles.

Recent studies have suggested that ribbon synapses rely on special adaptations of endocytic mechanisms (Lenzi et al., 2002; Holt et al., 2003, 2004; Paillart et al., 2003; Rea et al., 2004). Furthermore, the predominant mechanisms of endocytic mem-

Received July 16, 2004; revised Aug. 20, 2004; accepted Aug. 24, 2004.

This work was supported by the Howard Hughes Medical Institute; National Institutes of Health Grants NS36251 (P.D.), EY012373 (S.E.B.), and EY06641 (J.B.H.); a Human Frontiers long-term fellowship to M.H.; and Molecular and Cellular Biology Training Grant 5T326M07270 to H.A.V. We thank John Ngai (University of California, Berkeley, CA) for kindly sending the zebrafish brain cDNA library and Ji-fang Zhang (University of Pennsylvania, Philadelphia, PA) for kindly sending us the SH3p8-GST clone. We thank Irina Ankoudinova and Greg Niemi for technical assistance during the course of this study. We also thank John Saari and Visvanathan Ramamurthy for their critical reading of this manuscript.

Correspondence should be addressed to Dr. Susan E. Brockerhoff, Department of Biochemistry, University of Washington School of Medicine, Box 357350, Seattle, WA 98195. E-mail: sbrocker@u.washington.edu.

DOI:10.1523/JNEUROSCI.2892-04.2004

Copyright $\odot 2004$ Society for Neuroscience $\quad$ 0270-6474/04/248641-10\$15.00/0 brane retrieval may vary at different types of ribbon synapses. For example, synaptic terminals of retinal bipolar cells take up large plasma membrane fragments by bulk endocytosis to generate endosome-like structures (Lenzi et al., 2002; Paillart et al., 2003). In contrast, membrane recycling appears mediated primarily by small vesicles at cone pedicles under steady-state conditions (Rea at al., 2004).

Ribbons are unanchored, and synaptic vesicles aggregate in the cone photoreceptor terminals of the zebrafish vision mutant $n r c$ (Allwardt et al., 2001). The arciform density, which is thought to anchor ribbons to the presynaptic membrane (Ladman, 1958), is absent in the majority of $n r c$ photoreceptor terminals (Allwardt et al., 2001). The nrc synaptic malformities are associated with blindness and defective synaptic transmission between cones and bipolar cells characterized by pronounced asynchronous oscillations in the electroretinogram response (Allwardt et al., 2001; Van Epps et al., 2001). Unlike the photoreceptor synapse, the bipolar and pineal ribbon synapses, as well as conventional synapses, seem morphologically normal in $\operatorname{nrc}$ (Allwardt et al., 2001). The $n r c$ mutant therefore presents the opportunity to investigate unique properties of ribbon synapses, as well as differences between specific types of ribbon synapses.

In the present study, we used positional cloning to identify the $n r c$ mutation as a premature stop codon in the gene encoding synj1. Synj1 is a polyphosphoinositide phosphatase, the enzymatic activity of which regulates clathrin-mediated endocytosis and the actin cytoskeleton in conventional synapses (Sakisaka et al., 1997; Cremona et al., 1999; Harris et al., 2000; Kim et al., 2002; 
Stefan et al., 2002; Schuske et al., 2003; Verstreken et al., 2003). Evaluation of Synj defects in mouse, nematode, lamprey, and fly reveal abnormal vesicle maintenance and cytoskeletal matrix (Cremona et al., 1999; Gad et al., 2000; Harris et al., 2000; Kim et al., 2002; Schuske et al., 2003; Verstreken et al., 2003). PI(4,5) $\mathrm{P}_{2}$ acts as a cofactor both in the nucleation of actin and in the recruitment and assembly of clathrin coats and its accessory factors. The role of SynJ1 in ribbon synapses has not been characterized previously. $n r c$ cone synapses reveal a novel role for Synj1 in synapse architecture. Our study shows that Synj1 is essential for proper cone photoreceptor ribbon synapse structure, function, and vesicle maintenance in the cone pedicle.

\section{Materials and Methods}

Zebrafish maintenance and behavioral screening. The nrc mutant was originally identified in a behavioral screen for blind zebrafish (Brockerhoff et al., 1995). Zebrafish were maintained as described previously (Westerfield, 1994) on a 10/14 hr light/dark cycle. $n r c^{a 14}$ larvae were isolated and screened for the optokinetic response (OKR) as described previously (Brockerhoff et al., 1995). The $n r c^{a 14}$ mutation is recessive and segregates as a simple Mendelian allele. $n r^{a 14}$ have no OKR in white light of any intensity (Allwardt et al., 2001). However, they do spontaneously move their eyes, suggesting the mutation does not affect eye movement. $\mathrm{Mu}$ tant larvae normally die between 10 and $13 \mathrm{~d}$ post fertilization (dpf).

Orientation of larvae was scored by first placing five 5-6 dpf larvae in a Petri dish. The dish was then swirled, and the orientation of larvae was scored after the water stopped moving. This was repeated four times with 5 min between trials.

The startle response was scored by first placing 5-6 dpf larvae in a 12-well tissue culture plate. Two to three wild-type (WT) larvae were placed in one well, and three $n r c$ larvae were placed in a second well. The plate was then tapped from a $1.5 \mathrm{~cm}$ height with tweezers $\sim 7 \mathrm{~cm}$ from the larvae. Tapping was repeated after $30 \mathrm{sec}$. Larvae were videotaped, and the distance traveled during $0.33 \mathrm{sec}$ after the stimulus was calculated using the public domain NIH Image program developed at the National Institutes of Health (available at http://rsb.info.nih.gov/nih-image/). The experiment was repeated with 12 sets of larvae.

Positional/candidate cloning. A zebrafish bacterial artificial chromosome (BAC) library (Incyte Genomics, Fremont, CA) was screened with PCR primers designed to expressed sequence tag (EST) fb79h03, simple sequence length polymorphism (SSLP) Z7504, and synj1 EST fb02f11. The EST fb79h03 was mapped to BAC88i17. The SSLP Z7504 was mapped to BAC14p23. The fb02f1 1 synj1 EST was mapped to BAC56h15. The $1500 \mathrm{~kb}$ on each end of BAC56h15 were sequenced, and recombination analysis was conducted via denaturing HPLC.

The WT synj1 sequence was determined from the following sources. The sequence of bp 789-1500 and 2136-2756 was obtained from the synj1 EST fb02f11. The sequence of bp 705-789, 1500-1524, and 17161944 was obtained from reverse transcription (RT)-PCR from zebrafish larvae. The sequence of bp 789-948 was obtained by direct sequencing of BAC56h15. The sequence for bp 210-705, 1524-1716, 1944-2136, and 2294-2429 was obtained from the Sanger sequencing center (http:// www.sanger.ac.uk/Projects/D_rerio/). The sequence data of the $5^{\prime}$ untranslated region (UTR) through bp 210 were obtained from RT-PCR from a zebrafish brain cDNA library kindly donated by John Ngai (University of California, Berkeley, CA). Finally, bp 2756 through the 3' UTR were obtained by screening the plated brain cDNA library. All regions of the gene were sequenced at least twice and most several times from multiple sources.

In situ hybridization. An antisense RNA probe was transcribed from EcoR1 linearized fb02f11 EST plasmid using digoxigenin-labeled UTP and T7 RNA polymerase as described by the manufacturer (DIG RNA labeling kit; Roche Applied Sciences, Indianapolis, IN). A sense RNA probe was transcribed from XhoI linearized fb02f11 EST plasmid using digoxigenin-labeled UTP and T7 RNA polymerase. These probes cover a $1.99 \mathrm{~kb}$ region of synj1 corresponding approximately to exons 5-20, which includes part of the SacI domain and part of the 5' -phosphatase domain. A third probe to cone transducin $\alpha$ subunit was used as a control
(Brockerhoff et al., 2003). Whole-mount in situ hybridization experiments on 5-6 dpf larvae was done as described previously (Brockerhoff et al., 1997). Embryos were developed $1 \mathrm{hr}, 20 \mathrm{~min}$ at room temperature with 4-nitro blue tetrazolium chloride and 5-bromo-4-chloro-3 inolylphosphate (Boehringer Mannheim, Indianapolis, IN).

Real-time PCR. RNA was isolated from pools of 30-60 WT or homozygous mutant 6 dpf larvae using the RNAwiz reagent (Ambion, Austin, TX). RNA preparations were resuspended in $10 \mu \mathrm{l}$ of DEPC-treated water. RNA was then DNase treated for $30 \mathrm{~min}$ at $37^{\circ} \mathrm{C}$. Phenol extraction and RNA precipitation with $100 \%$ ethanol (EtOH) was performed. RNA was washed with $75 \% \mathrm{EtOH}$, dried, and resuspended in $25 \mu \mathrm{l}$ of DEPC-treated water.

RNA $(1.3 \mu \mathrm{g})$ was reverse transcribed with Thermoscript Reverse Transcriptase (Invitrogen, Carlsbad, CA) with synj1-specific primer SynjEx20.R3 (CCTCGCCAAAATTAGCAAAC). Conditions for reactions were as described by manufacturer's manual (Thermoscript RT PCR system; Invitrogen) at $50^{\circ} \mathrm{C}$ overnight. cDNA was RNase $\mathrm{H}$ treated for $30 \mathrm{~min}$ at $37^{\circ} \mathrm{C}$. cDNA was then amplified with Sybr green PCR master mix (Applied Biosystems, Foster City, CA) with either synj1 or EF1 $\alpha$ control primers. synj1 primer pair1 was SynjEx9.F1 (ACTGCTTGGACCGAACAAAC) and SynjEx11.R3 (TCGTGCTTTATCTGCCAGGTC); synj1 primer pair 2 was 5'UTR.F1 (GCAAGACAGGCACAACTCTG) and SynjEx3.R3 (GGACTTTTCCCACTGAGCTG); synj1 primer pair 3 was SynjEX3.F1 (CAGCTCAGTGGGAAAAGTCC) and SynjEx4.R4 (CTCAGAAGCCAGTCGTCACA); synj1 primer pair 4 was SynjEx10.F2 (AAGCCATGGGTTTGACAGAG) and SynjEx11.R4 (GCTTGTCGTGAGAAGCGCTCG). The sequence of EF1 $\alpha$ control primers was GTGCTGTGCTGATTGTTGCT and TGTATGCGCTGACTTCCTTG. Fluorescence and melting curves of reaction products were monitored with an Opticon (MJ Research, South San Francisco, CA).

Morpholinos. Fish were given injections of 2.5, 5, 10, or $20 \mathrm{mg} / \mathrm{ml}$ morpholino diluted in Danieau buffer [in mM: $58 \mathrm{NaCl}, 0.7 \mathrm{KCl}, 0.4$ $\mathrm{MgSO}_{4}, 0.6 \mathrm{Ca}\left(\mathrm{NO}_{3}\right)_{2}$, and 5.0 HEPES, pH7.6] and $0.05 \%$ phenol red as a dye marker. A morpholino is a modified antisense oligonucleotide that specifically blocks translation of a targeted gene (Corey and Abrams, 2001). synj1 1 morpholinos were synj1-MO-A with a sequence ACGATAACCTTTACTGAATGCCATG and synj1-MO-B with a sequence TCGACAACCTATTTCAGACCTGT. These are both translationblocking morpholinos targeting zebrafish synj1. Control morpholinos were either a standard control from Gene Tools (Philomath, OR) that has no target and no significant biological activity with a sequence CCTCTTACCTCAGTTACAATTTATA, or a sense synj1 morpholino with a $3^{\prime}$ carboxyfluorescein tag with a sequence CATGGCATTCAGTAAAGGTTATCGT. Controls gave identical results. The embryos were injected at the one- to four-cell stage to a total volume equaling approximately one cell at the eight-cell stage. Microinjections were done in accordance with Meng et al. (1999). Embryos were then raised to $5 \mathrm{dpf}$ and evaluated for an OKR. All embryos were compared with uninjected siblings or uninjected and control injected siblings. A "robust OKR" was qualified as consistent stripe tracking in both directions. A "reduced OKR" was qualified as inconsistent and infrequent stripe tracking. "No OKR" larvae displayed no stripe tracking under two trials of three rotations of the drum in both directions.

Microscopy. Dark-adapted (at least $2 \mathrm{hr}$ ) or light-adapted embryos were fixed, embedded, and sectioned as described previously (Brockerhoff et al., 1995). For electron microscopy (EM), 60-80 nm sections were analyzed. For light microscopy, $10-15 \mu \mathrm{m}$ sections were analyzed. Alexa Fluor 488 phalloidin staining was conducted as described by the manufacturer (Molecular Probes, Eugene, OR). Immunofluorescence microscopy with frozen sections of mouse retina was performed as described (De Camilli et al., 1983). Briefly, 4\% paraformaldehyde-fixed retina was sectioned ( $7 \mu \mathrm{m}$ thick). Sections were incubated with rabbit polyclonal anti-rat Synj1 proline-rich domain sera (1:100) (Haffner et al., 2000), followed by incubation with Oregon green-conjugated anti-rabbit IgG secondary antibody (Molecular Probes).

Phosphate release assay. Total cytosolic protein preparations were obtained by homogenization of 25 or $556 \mathrm{dpf}$ zebrafish embryos in the following (in mM): 25 Tris, $\mathrm{pH} 8.0,250$ sucrose, $500 \mathrm{KCl}, 10 \mathrm{MgCl}_{2}, 2$ EGTA, and 1 DTT containing Complete Mini, EDTA-free Protease In- 
hibitor mixture (Roche Applied Sciences). Homogenates were ultrafuged $45 \mathrm{~min}$ at $50,000 \mathrm{rpm}$ at $4^{\circ} \mathrm{C}$ in a TLA 100.2 rotor (Beckman Instruments, Fullerton, CA). The supernatants containing cytosolic proteins were passed over NAP 5 columns (Amersham Biosciences, Piscataway, NJ) and eluted with (in mM) 30 HEPES, pH7.4, 1 EGTA, $1 \mathrm{MgCl}_{2}$, and $100 \mathrm{KCl}$. Six independent WT and six independent mutant pools of larvae were assayed in triplicate with and without lipid substrate added. All embryos of mutant pools were screened for an OKR at least twice. Production of free phosphate was assayed as described (Harder et al., 1994) For three WT and three mutant pools, $10 \mu \mathrm{g}$ of cytosolic protein was incubated with or without $2 \mu \mathrm{g}$ of synthetic phosphoinositide 4 phosphate [PI(4)P] for $15 \mathrm{~min}$ or $2 \mu \mathrm{g}$ of cytosolic protein was incubated with or without $1 \mu \mathrm{g}$ of phosphoinositide 4,5 bisphosphate $\left[\mathrm{PI}(4,5) \mathrm{P}_{2}\right]$ for $15 \mathrm{~min}$ in the following (in mM): 30 HEPES, pH7.4, 1 EGTA, $1 \mathrm{MgCl}_{2}$, and $100 \mathrm{KCl}$ at $37^{\circ} \mathrm{C}$. Free Pi generated in the assay was measured by malachite green assay using a microplate reader at $620 \mathrm{~nm}$. Data were corrected for background activity by subtracting - PIP absorbance from +PIP absorbance for each reaction. For a second set of three WT and three mutant pools, $10 \mu \mathrm{g}$ of cytosolic protein was incubated with $1 \mu \mathrm{g}$ of synthetic PI(4)P for $45 \mathrm{~min}$ or $1 \mu \mathrm{g}$ of cytosolic protein was incubated with $1 \mu \mathrm{g}$ of $\mathrm{PI}(4,5) \mathrm{P}_{2}$ for $20 \mathrm{~min}$. These conditions gave similar results to the first conditions (data not shown).

Endophilin overlay assay. SH3p8-GST encoding full-length rat endophilin 2 fused to glutathione $S$-transferase (GST) was kindly provided by Ji-fang Zhang (University of Pennsylvania, Philadelphia, PA). The fusion protein was produced in Escherichia coli and purified as described previously (Chen et al., 2003). WT and $n r c$ larvae, 5-6 dpf, were killed by placing a Petri dish containing the larvae on ice for $\sim 10 \mathrm{~min}$. Brains were removed using 21.5 gauge needles. Five brains were placed in a Microfuge tube, briefly spun to remove excess liquid, and then homogenized for 10 sec on ice in $1 \times$ SDS sample buffer. Samples were boiled and treated with benzonase (Roche Applied Sciences) before loading onto a 7.5\% SDS polyacrylamide gel. The gel was transferred for $4 \mathrm{hr}$ at room temperature to immobilon PVDF membranes, blocked overnight in 5\% nonfat milk in Tris-buffered saline with Triton, and then probed for $4 \mathrm{hr}$ with 1-10 $\mu \mathrm{g} / \mathrm{ml} \mathrm{SH3p8-GST} \mathrm{in} \mathrm{blocking} \mathrm{solution.} \mathrm{Bound} \mathrm{endophilin} \mathrm{was} \mathrm{detected}$ with HRP-conjugated anti-GST antibody and the ECL detection system (Amersham Biosciences).

Anti-Synj1 Western blot. Western blot was conducted as described for the endophilin overlay assay, with the following exceptions. Instead of endophilin, the blot was incubated with rabbit polyclonal anti-rat Synj1 proline-rich domain sera $4 \mathrm{hr}$ at 1:5000 (Haffner et al., 2000) in blocking solution. Primary antibody was detected with alkaline phosphataseconjugated anti-rabbit secondary antibody at 1:500 (Sigma-Aldrich, St. Louis, MO).

\section{Results}

\section{The $n r c$ gene is synj1}

The zebrafish mutant $n r c$ was identified in a screen for mutations that affect a vision-dependent behavior, the OKR (Brockerhoff et al., 1995). The abnormal electroretinogram and ultrastructure of the $n r c$ retina (Allwardt et al., 2001; Van Epps et al., 2001) indicate that the product of the $n r c$ gene plays an important role at the cone photoreceptor ribbon synapse. In addition to vision defects, $n r c$ larvae swim abnormally and do not orient themselves properly. WT larvae at 5-6 dpf orient dorsal side up $98+/-3 \%$ (SD; $n=55)$ of the time. In contrast, $n r c$ larvae at 5-6 dpf orient dorsal side up only $28+/-13 \%(\mathrm{SD} ; n=55)$ of the time. $n r c$ larvae display a normal startle response [ratio of $n r c / W T$ distance traveled after stimulus, $1.03+/-0.06$ (SEM; $n=36 n r c$ and 30 wild type)]. Gross anatomy and FM1-43 staining of the nrc ear and lateral line look grossly normal (data not shown). The balance defect in nrc may, however, be attributable to abnormal ribbon architecture and synaptic transmission at hair cells, but this was not investigated in this study.

To identify the $n r c$ gene, we first mapped it to a $1.3 \mathrm{cM}$ region on linkage group 10 (Van Epps et al., 2001). We then identified closely linked ESTs and Z-markers (simple sequence length polymorphisms) (Shimoda et al., 1999) in the nrc critical region by recombination analysis of 5206 meioses using single-strand conformation polymorphisms (Fig. $1 A$ ). The closest linked markers were EST fb79h03 and Z-marker Z7504. This narrowed the critical region to $0.24 \mathrm{cM}(\sim 156 \mathrm{~kb})$ (Postlethwait et al., 1994), and a chromosomal walk using a zebrafish BAC library (Incyte Genomics) was initiated.

During the positional cloning, EST fb02f11, encoding $1.99 \mathrm{~kb}$ of the synj1 gene, was placed on the zebrafish radiation hybrid panel (Hukriede et al., 1999) (most recent maps available at http://zfin.org/cgi-bin/webdriver?MIval = aa-refcrosslist.apg) on linkage group 10. synj1 was a good candidate gene for the nrc mutation, based on its high level of expression in nerve terminals (McPherson et al., 1996) and its importance in synaptic function (Cremona et al., 1999; Harris et al., 2000; Luthi et al., 2001; Verstreken et al., 2003). Therefore, the genetic linkage of synj1 and $n r c$ was assessed. Scorable polymorphisms for synj1 were obtained by screening a BAC library with primers from fb $02 \mathrm{f} 11$. The ends of BAC56h15, containing the synj1 gene, were sequenced, and recombination analysis was done using denaturing HPLC. One end contained two recombinants, and the other end contained zero recombinants of 5206 meioses. The BAC containing synj1 was therefore at the $n r c$ locus and at most $0.04 \mathrm{cM}(\sim 26 \mathrm{~kb})$ (Postlethwait et al., 1994) from the $n r c$ mutation. synj1 therefore became a strong candidate for the $n r c$ gene.

The full-length WT synj1 sequence (Fig. $1 B$ ) was obtained from a zebrafish brain cDNA library (kindly provided by J. Ngai), from EST fb02f11, from the Sanger sequencing center, and from BAC56h15 (see Materials and Methods). The cDNA encoding zebrafish synj1 is $4.8 \mathrm{~kb}$ long. The protein sequence is $60 \%$ identical to human Synj1 and 40\% identical to human Synj2 (Fig. 1 E, dendrogram). Synj 1 contains a SacI phosphoinositide phosphatase domain (81\% identity with human), a $5^{\prime}$ phosphoinositide phosphatase domain (79\% identity with human), and a prolinerich C-terminal domain (PRD). The catalytic sites of the zebrafish SacI and 5'-phosphatase domains are highly conserved. Amphiphysin (Cestra et al., 1999), endophilin (Cestra et al., 1999; Ringstad et al., 2001), and putative clathrin binding domains ( $\mathrm{Ha}$ et al., 2003) are also highly conserved (domains highlighted in Fig. 1). Similar to the mouse and human synj1 genes, zebrafish synj1 encodes stop codons at aa 1309 and 1565. This creates a transcript encoding two splice variants of Synj1, 145 and $172 \mathrm{kDa}$ in size.

To screen the nrc synj1 gene for mutations, we sequenced RT-PCR products from pools of $n r c$ larvae. The analysis revealed a mutation, C to T, that converts ARG 499 to a stop codon (Fig. $1 \mathrm{~B})$. This premature stop codon is at the most $\mathrm{C}$-terminal region of the SacI domain. The mutation was confirmed by sequencing genomic DNA from 10 individual $n r c$ (AB/WIK strain zebrafish) and 5 WT (three AB strain, two WIK strain zebrafish) larvae. The mutation was found in genomic DNA from 10 of 10 nrc larvae and 0 of 5 WT larvae.

\section{Synj1 expression}

To determine whether the premature stop codon induces degradation of the mutant RNA, we performed quantitative real-time PCR analyses. Multiple primers spanning much of the cDNA (see Materials and Methods) revealed no difference between WT and $n r c$ levels of synj1 RNA, suggesting there is no nonsense mediated degradation of $n r c$ RNA (data not shown).

To evaluate localization of WT synj1 in zebrafish larvae, we performed RNA whole-mount in situ hybridization. The synj1 
antisense probe, but not the sense control, revealed intense staining in the brain (Fig. $1 C)$, consistent with the localization of Synj throughout the nervous system and in the retina of other organisms (McPherson et al., 1996; Harris et al., 2000; Verstreken et al., 2003). No antibody tested cross-reacted with zebrafish Synj1 in immunohistochemistry (Gad et al., 2000; Haffner et al., 2000). However, in another vertebrate retina, the mouse, Synj1 is concentrated in nerve terminals of both the outer plexiform layer (OPL) and inner plexiform layer (IPL) (Fig. 1D). Only the rat PRD domain antibody (Haffner et al., 2000) cross-reacted with zebrafish Synj1 on a Western blot (see below).

\section{Knock-down of Synj1 produces a nrc-like phenotype}

To further confirm that synj1 encodes the $n r c$ gene, we reproduced the $n r c$ phenotype by injecting synj1 morpholinos. A morpholino is a modified oligonucleotide that blocks translation of the targeted gene (Corey and Abrams, 2001). Key aspects of the nrc mutant phenotype are the absence of an OKR, abnormal balance, and the presence of unanchored ribbons in the OPL, but not in the IPL (Allwardt et al., 2001). In light microscopy sections, the nrc OPL appears thin and patchy. We evaluated embryos injected with two different synj1 morpholinos for these phenotypes. WT embryos were injected either with a control morpholino or with synj1 antisense morpholinos A and/or B at the oneto four-cell stage. Embryos were then scored for the OKR at $5 \mathrm{dpf}$ (see Materials and Methods).

Figure $2 \mathrm{~A}$ shows that injection of synj1 morpholinos diminished OKR responses significantly compared with controls. The percentage of affected embryos increased with morpholino concentration. Larvae with no OKR also displayed $n r c$-like swimming and balance behavior. synj1-MO-A was more potent than synj1-MO-B, but both had similar OKR effects. The effect of injection of both morpholinos together was additive. The injected larvae showed no gross abnormalities (Fig. 2B). Thus, injections of synj1 morpholinos induce the nrc behavioral phenotype.

To determine whether synj1 morpholino injections cause a morphological defect, we analyzed retinas of OKR-deficient synj1 morpholino-injected larvae by light and electron microscopy. Retinas of larvae injected with synj1 antisense synj1-MO-A had photoreceptors, secondary neurons, and ganglion cells, as did control injected larvae (Fig. 3A). Discs were stacked normally in the photoreceptor outer segments (Fig. 3B). However, the retinas of synj1 morpholino-injected larvae appeared more disordered than in the nrc mutant at a similar stage (Allwardt et al., 2001).

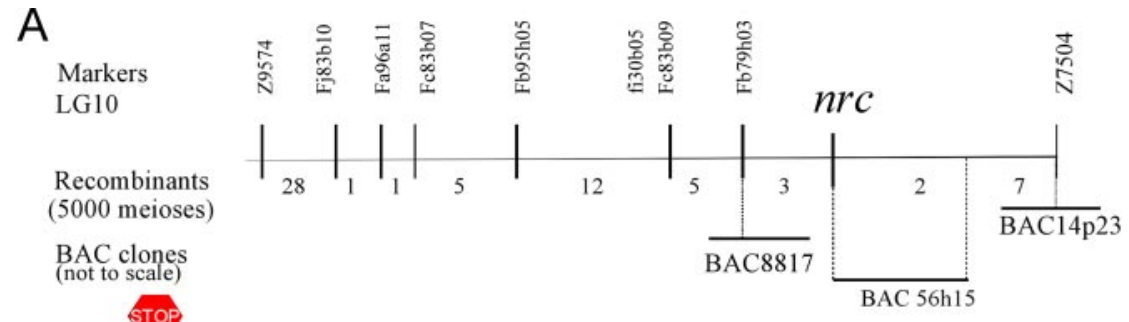

B MAFSKGYRIYHKLDPPPYSVIVETRNREECLMFESGAVAVLSAAEKETIKASYTKMLDA DWLLRLMCGGVEIRTIYAGHKQAKACVISRLSSERAGTRFNVRGTNDDGQVANFVETE QIIFLDDKVSSFIQIRGSIPLFWEQPGIQVGSHRVKL_SRGFEANAPAFERHFSALKRL.YGKQ LIINLLGMKEGEHMLSKAFQSHLKASEHSNAVKMLNFDYHQMVKGGKTEKLQTVL KPQ ISKF VEDCDFFYYSGETGIQRCQSGTIRSNCLDCLDRTNSVQAFIALEMLPKQLEAMGLTE KPQLVARFQEVFRSMWSTNGDSISKIYAGTGALDGKAKGGKL.KDGARSVTRTIONNFFD KPQLVARFQEVFRSMWSTNGDSISKIYAGTGAL.DGKAKGGKLKRDGARSVTRTIQNNFFD
SSKQEAIDILRLGSTLNSDLADKABALLTTSSLYYSEPILQSASPRVLLGMCONHFKYTRP SSKQEAIDILRLGSTLNSDLADKABALLTTSSL.YVSEPILQSASPRVLLGMCQNHFKYTRP

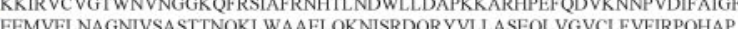
FRDV FIRDVAVDTVKTGMGGATGNKGGVAIRMLFHTTSICFVCSHFAAGQSQVKERNDDYNE
ARKLSFPMGRLL YSHDYVFWCGDFNYRINIPNEEVKELIRQQNWDALIGGDQL VEQKNAGQVFRGFIEGKLDFAPTYK YDLFSEDYDTSE KCRTPAWTDRVL WKRRKWNFDKTAEELELNVVGAPVNEEEQYPWSPGDLKYYGRAELKTSDHRPVVAIIDVDILEVDPEARHQVYKEVI ALQGPPDGTIL VSLCSSGPDDYFDD LLIDDLLDKFANFGEVILIRF VEEKMWVTFLEGYSALAALSLSGSTVNGKTIDIRLRSPGWIKSLEEE MSVERICGSIPTSTSSTLLAENSDLGEEYDMEGDVDEEVEDILPQHLQPGAGMDLSASPATSPRTSPCPSPTHGEPAPPIRPSRAPPRTAGPPQ GSPVDGQPAGAPFSQGLEPKRPPPPRPNAPPARPAPPQRPPPPSGRGQATGPAPGGPRPIPPRAGVISVTPQARPPPPAHPGAPRPTAEVHPG APRPSPDNHPGAPRPTAEPQSKPSELPLGPPPTLPGPVRPQMTSPMQPQSVSPVQPPVQPQLPPPIQSQLPPPMQPTLPAPLMPQQAPQTSAG AGAAAAPQPGLASPKPPPRSRSSHALPPESAPAPTTQQEQSSG*QAKNMNGVQREAQWNLDPFDMLNPQSLFQNTPFTASLPRSSSSSTSTP SPSSSSSTLPSNLSLFSAPDTSSASCLLAPPAPSRSKSQETLRCSPNPFLTDIQPRPNSTNPFTSGLQSSPRRSLTPYFYTQMQASKPDFNRAMS AVGHSSTLPPTFSRQQSLVTATAPAPNKQTQKWVTFDDDLDFLSKRVGTGPLASPLPFPQTQSSFPSSGFGMDNNWASLPTSAFPAIPPPVPI
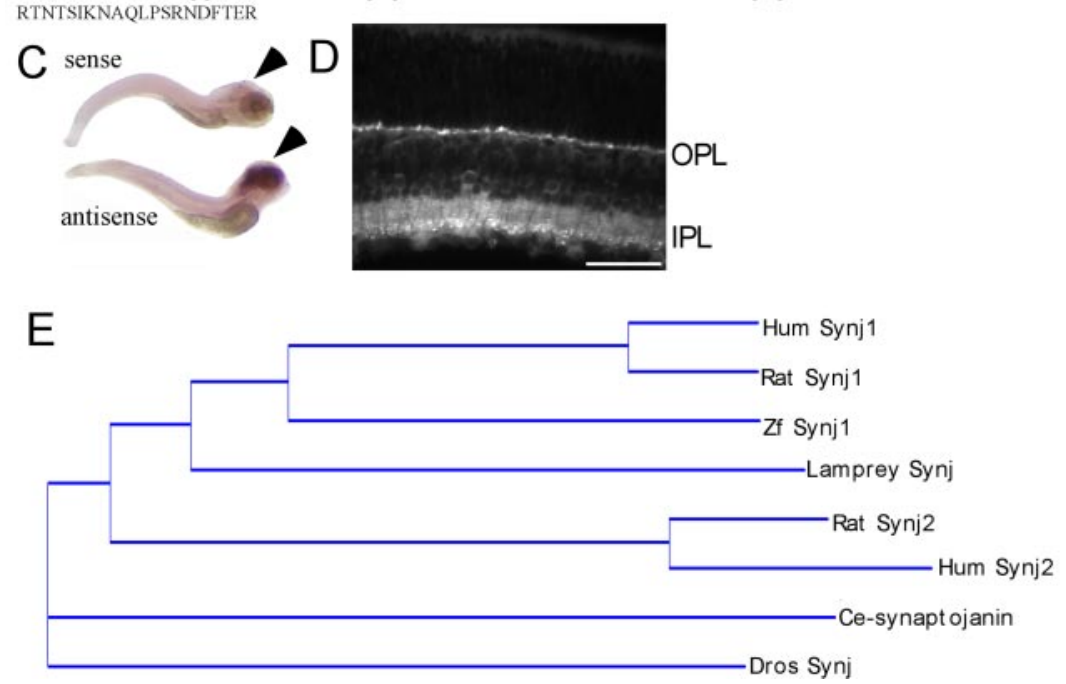

Figure 1. The nrc mutation is a stop codon in synj1, and Synj 1 is expressed in brain and retina. A, Positional cloning defines the critical genetic region for the nrc mutation. The number between genetic markers represents the number of recombinants identified. B, Schematic of Synj1 domains, Sacl (Sac1), 5'-phosphatase (5'Ptase), and proline-rich protein binding domain (pppp). The site of the nrc mutation is shown as a stop on the domain schematic. DNA sequence wave data of the mutation site reveals $C$ to $T$ nonsense mutation in $n$ rclarvae. The full-length protein sequence of zebrafish Synj1 is shown with the mutation site demarcated in red. The border between phosphatase domains is marked by a bold line. The green rectangle demarcates the putative clathrin-binding domain. The putative amphiphysin-binding domain is outlined by a blue rectangle, and the endophilinbinding domain is demarcated by a red rectangle. C, Antisense, but not sense, RNA in situ hybridization reveals synj 1 in WT $6 \mathrm{dpf}$ larval brain. The arrowheads point to the brain region. $D$, Two-week-old mouse retinal section immunohistochemistry with anti-Synj1 proline-rich domain antibody localizes Synj1 to the OPL and IPL. Scale bar, $50 \mu \mathrm{m}$. E, Dendrogram shows the amino acid conservation between zebrafish Synj1 and other previously published Synjs. Zebrafish (Zf) Synj1 is more similar to human and rat Synj1 than to human (Hum) and rat Synj2. Dros, Drosophila. The dendrogram was generated using Vector Nti version 9.0 (Informax, Bethesda, MD). The GenBank accession number for zebrafish synaptojanin is AY736013.

The OPL of synj1 morpholino-injected larvae was unusually thin, similar to the $n r c$ mutant (Fig. 3A). Ribbons were predominantly unanchored (85\%) in the OPL (Fig. 4) (77 of 92 ribbons unanchored; $n=3$ larvae; 64 synapses) and anchored (84\%) in the IPL (data not shown; 27 of 32 ribbons anchored; $n=3$ larvae; 29 synapses) of synj1 morphant fish similar to $n r c$ larvae (Allwardt et al., 2001). In contrast, retinas of larvae injected with control morpholinos had anchored ribbons in both the OPL and IPL (Fig. 4 and data not shown) similar to WT larvae. Additional changes characteristic of $n r c$ mutant cone pedicles, such as vesicle-free, 


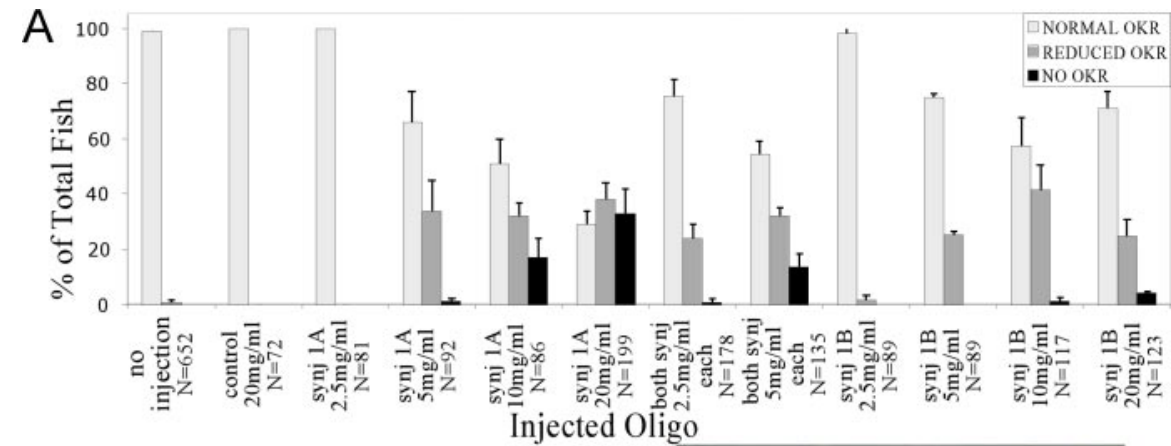

B
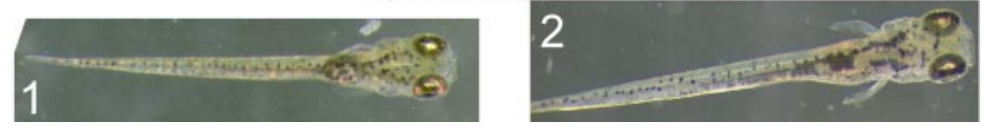

Figure 2. synj1 morpholinos phenocopy the nrc visual behavior defect. $A$, Percentage of total larvae with no OKR, normal OKR, or reduced OKR plotted for each injection scenario. $B$, The overall morphology of control ( $20 \mathrm{mg} / \mathrm{ml}$ morpholino, robust OKR) (1) injected and synj1-M0-A (20 mg/ml, no OKR) (2)-injected larvae are grossly indistinguishable. Representative 5 dpf larvae are shown.

matrix-rich regions (Fig. 4, bottom, asterisk) (see below), were observed in synj1 morpholino-injected synapses. These results indicate that the synj1 morpholino-injected fish have a retinal morphology phenotype very similar to the nrc mutant and support the conclusion that the $n r c$ mutation inactivates the synj1 gene.

\section{Phosphoinositide phosphatase activity is reduced in nrc mutants}

For additional confirmation that the $n r c$ mutation disrupts Synj1, we analyzed phosphoinositide phosphatase activity in extracts from whole WT and nrc larvae. There are two phosphoinositide phosphatase domains in Synj: a SacI homology domain, which can dephosphorylate several positions of the inositol ring, and a central inositol 5' -phosphatase domain. The substrates for the SacI domain are $\mathrm{PI}(4) \mathrm{P}$, phosphoinositide 3 phosphate, and phosphoinositide 3,5 phosphate. The substrates for the inositol 5 ' -phosphatase domain are $\mathrm{PI}(4,5) \mathrm{P}_{2}$ and phosphoinositide 3,4,5 trisphosphate $\left[\mathrm{PI}(3,4,5) \mathrm{P}_{3}\right]$ (Guo et al., 1999; Nemoto et al., 2001). To examine the activities of both domains, we assayed release of phosphate when cytosol from either WT or nrc larvae was incubated with $\mathrm{PI}(4) \mathrm{P}$ or $\mathrm{PI}(4,5) \mathrm{P}_{2}$.

Release of free phosphate in $n r c$ extracts was reduced by $23 \%$ [PI(4)P substrate] and $21 \%\left[\mathrm{PI}(4,5) \mathrm{P}_{2}\right.$ substrate $]$ compared with WT extracts (Fig. $5 A, B$ ). This indicates that overall both PI(4)P and $\mathrm{PI}(4,5) \mathrm{P}_{2}$ phosphatase activities are compromised in the $n r c$ mutant. We hypothesize that the remaining phosphatase activity is attributable to other phosphoinositide phosphatases in the zebrafish whole larvae extracts. It is particularly notable that PI(4)P phosphatase activity is reduced in the nrc mutant because the nonsense mutation found in $n r c$ is at the most C-terminal amino acid of the SacI domain. The finding that PI(4)P phosphatase activity is reduced in the $n r c$ mutant suggests that a truncated but functional SacI domain is not present at significant levels in the mutant. The reduction in $\mathrm{PI}(4) \mathrm{P}$ and $\mathrm{PI}(4,5) \mathrm{P}_{2}$ phosphoinositide phosphatase activity indicates that the nrc mutation in synj1 causes a loss of function of zebrafish Synj1.

\section{The Synj1 protein is absent in nrc mutants}

To determine whether Synj protein was indeed absent in $n r c$ mutants, two independent approaches were used. First, we searched for a Synj1-immunoreactive band by Western blotting with an- tibodies raised against the proline-rich region of rat Synj1. A $150 \mathrm{kDa}$ protein (the predicted size of zebrafish Synj1) was recognized in WT, but not nrc, extracts (Fig. $5 C)$.

Second, we performed overlay assays with a major Synj-binding partner. Synj normally interacts with other proteins involved in clathrin-mediated endocytosis. One of these, endophilin, helps localize and stabilize Synj (Gad et al., 2000; Schuske et al., 2003; Verstreken et al., 2003). The binding site for the $\mathrm{SH} 3$ domain of endophilin is highly conserved in zebrafish Synj1 (Fig. 1). Zebrafish brain extracts were separated by SDS-PAGE, transferred, and probed in an overlay assay either with GST-rat endophilin or with GST-zebrafish transducin as a control. In WT brain extracts, GST-endophilin, but not GSTtransducin, binds a $\sim 150 \mathrm{kDa}$ protein (Fig. $5 D)$ that has the same electrophoretic mobility as the Synjimmunoreactive band (Fig. 5C). The $150 \mathrm{kDa}$ protein was missing from $n r c$ extracts, consistent with the absence of full-length Synj1 in $n r c$ (Fig. 5D). This result demonstrates that the interaction of endophilin with Synj is conserved in zebrafish and further confirms the absence of Synj in $n r c$ mutants. An $\sim 95 \mathrm{kDa}$ protein, corresponding to the predicted size of dynamin, binds to GSTendophilin (Ringstad et al., 1997) in both $n r c$ and WT larval brain extracts (Fig. 5D). Dynamin is the other major binding partner of endophilin besides Synj (Ringstad et al., 1999). Binding of GSTendophilin to dynamin serves as a positive control for protein loading and efficient endophilin binding in $n r c$ extracts. The endophilin overlay and Synj1 immunoblot together show fulllength Synj1 is absent in nrc extracts.

\section{nrc cone photoreceptor ribbon synapses: actin staining and vesicle traffic}

Synj1, via its ability to degrade $\mathrm{PI}(4,5) \mathrm{P}_{2}$, participates in clathrinmediated endocytosis and actin cytoskeleton rearrangement in conventional synapses (Sakisaka et al., 1997; Cremona et al., 1999; Gad et al., 2000; Harris et al., 2000; Raucher et al., 2000; Stefan et al., 2002; Verstreken et al., 2003). We analyzed the distribution of polymerized actin in WT and $n r c$ retinas by staining with phalloidin-conjugated to Alexa Fluor 488 (Fig. 6). The distribution of polymerized actin in the $n r c$ OPL $(n=8)$ appears patchy and irregular in comparison with the WT OPL. There are also regions that appear to have increased polymerized actin within the nrc synapse in comparison with wild type. This is consistent with the positive role of $\mathrm{PI}(4,5) \mathrm{P}_{2}$ on actin nucleation (for example, see Takenawa and Itoh, 2001). Increased polymerized actin is consistent with a null Synj1 phenotype.

We also revisited the previously described ultrastructure of cone photoreceptor ribbon synapses in nrc to further assess changes that could reflect defects in membrane traffic and actin cytoskeleton. EM was performed on cone pedicles of $n r c$ and WT $6 \mathrm{dpf}$ retinas in both light-adapted (Fig. 7A-E) and dark-adapted states (data not shown). At this age of development, cone pedicles, but not rod spherules, have formed completely. Several changes were observed in $n r c$ cone nerve terminals (Fig. 7). We confirmed the presence of a disrupted synaptic architecture (Fig. 7, compare $A, B$ ) and numerous unanchored ribbons (Fig. $7 B, C$ ), although some anchored ribbons were also present. Free ribbons 

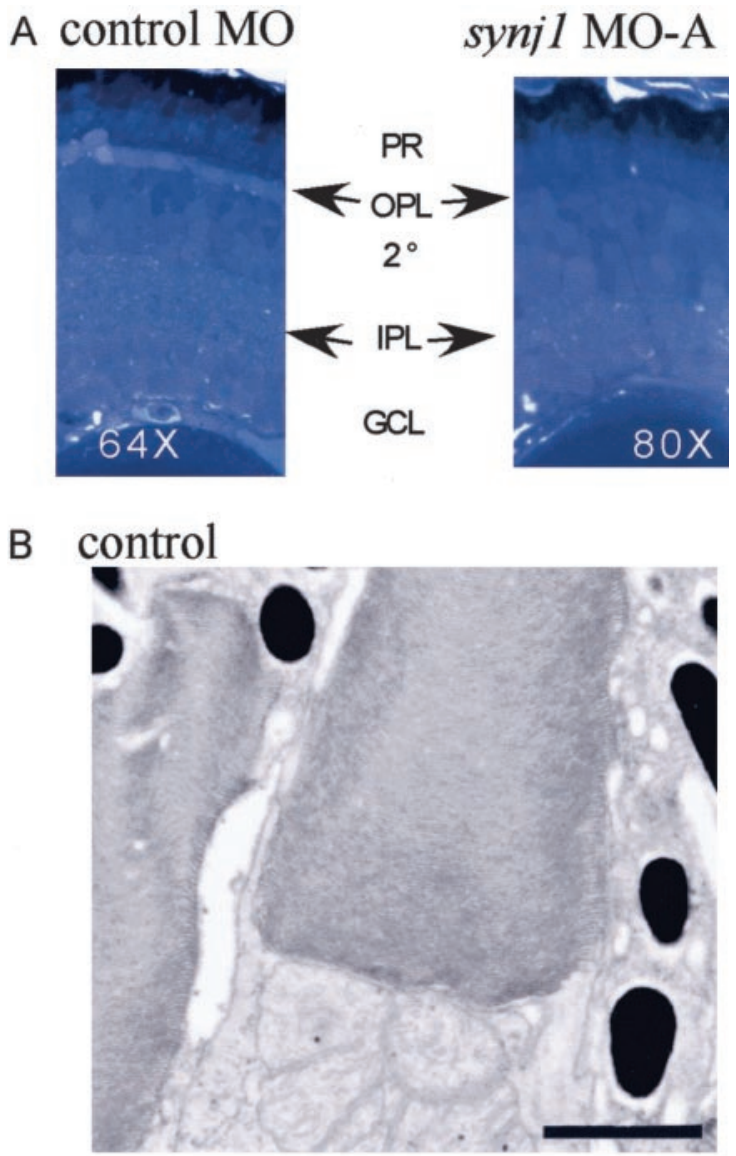

synil MO-A

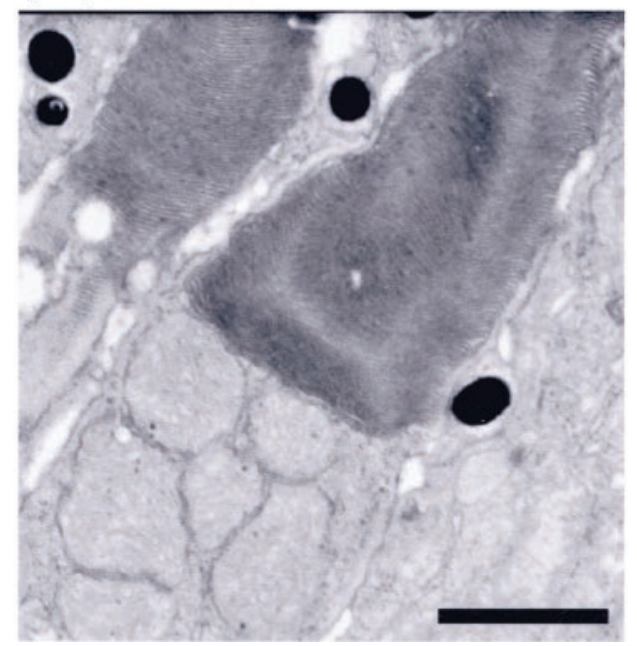

Figure 3. Retina of morpholino-injected larvae. $A$, Light microscopy of retinas from control ( $20 \mathrm{mg} / \mathrm{ml}$ morpholino, robust OKR) injected and synj1-MO-A ( $20 \mathrm{mg} / \mathrm{ml}$, no OKR)-injected 5 dpf larvae. The retina is grossly normal. Photoreceptors (PR), secondary neurons $\left(2^{\circ}\right)$, and ganglion cells (GCL) appear properly positioned in the laminated retina. The OPL and IPL are present. However, the OPL in synj1 morpholino-injected larvae appears thinner than in controlinjected larvae. B, Electron micrographs of photoreceptor outer segments from control (20 $\mathrm{mg} / \mathrm{ml}$ morpholino, robust OKR)-injected and synj1-M0-A ( $20 \mathrm{mg} / \mathrm{ml}$, no OKR)-injected $5 \mathrm{dpf}$ larvae. Both have formed outer segments with nicely stacked discs. Scale bar, $1 \mu \mathrm{m}$.

often aggregated into clusters separated by one row of vesicles (Fig. $7 C$ ). In addition, there were $\sim 50 \%$ fewer synaptic vesicles in $n$ rc versus WT cone synapses (Fig. 7E). These vesicles were distributed unevenly in the terminal, with vesicle-rich areas inter-
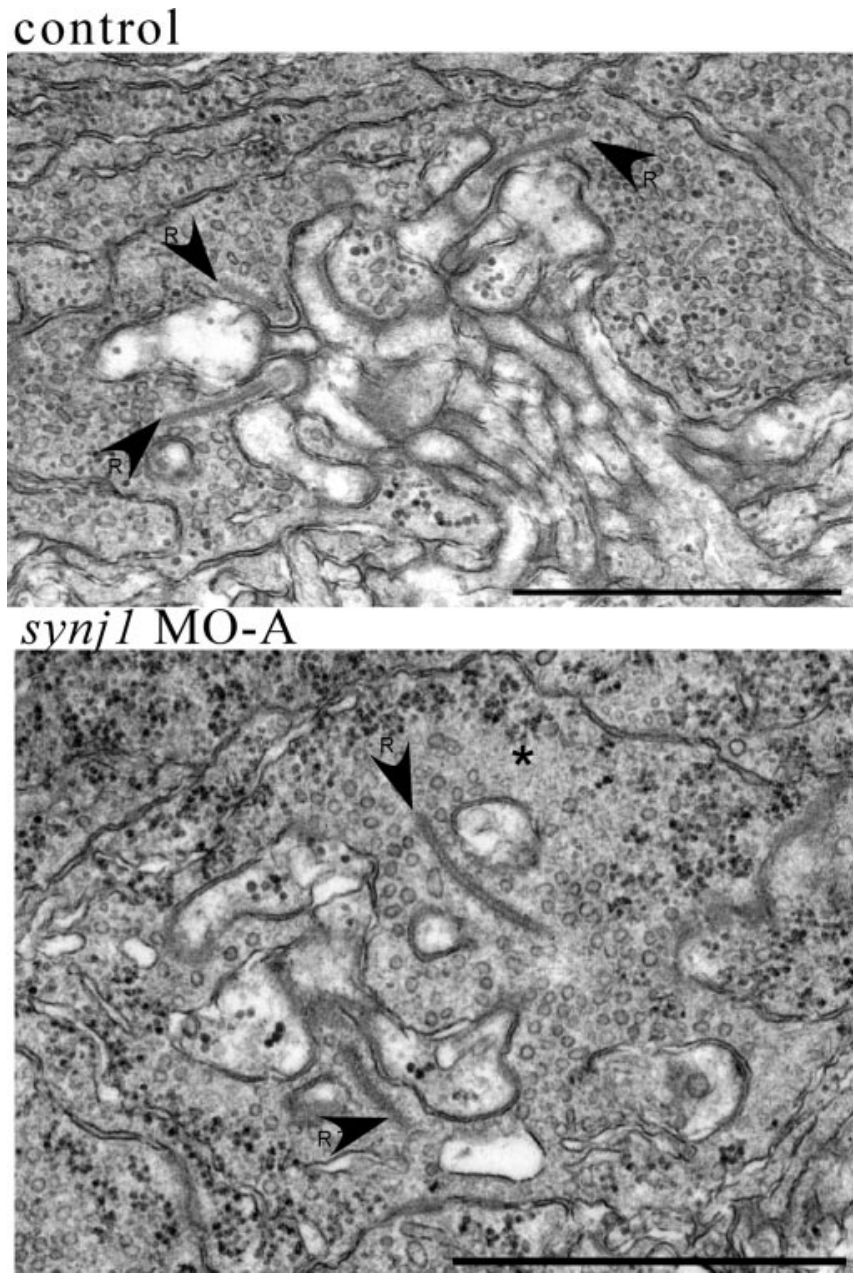

Figure 4. synj 1 morpholinos phenocopy the nrc ultrastructural retinal defects of the OPL. EM of the OPL of control ( $20 \mathrm{mg} / \mathrm{ml}$ morpholino, robust OKR)-injected and synj1-MO-A ( $20 \mathrm{mg} / \mathrm{ml}$, no $0 K R$ )-injected $5 \mathrm{dpf}$ larvae. Ribbon structures (R) are unanchored in the retina of MO-A larvae but not in controls. Matrix-rich areas ${ }^{*}$ ) devoid of organelles are also seen in MO-A-injected larvae, consistent with $n r c$ findings in this study (Fig. 6). Representative synapses are shown. Scale bar, $1 \mu \mathrm{m}$.

spersed with regions devoid of vesicles and rich in a dense cytomatrix (Fig. 7B, asterisk). Most likely, this is the actin cytoskeleton. Clathrin coats were difficult to detect, possibly because of the density of the cytomatrix surrounding vesicles. This prevented a morphometric analysis of clathrin-coated vesicles. However, several vesicles with what appeared to be a partial or complete coat were seen (Fig. $7 B$, insets). Clusters of vesicles away from the active zone and peculiar rows of vesicles, like "beads on a string," were often observed, as seen at synapses of Drosophila and Caenorhabditis elegans Synj and endophilin mutants (Schuske et al., 2003; Verstreken et al., 2003). We also found a 10 times increase in endosomal area and 5 times increase in endosome membrane perimeter in $n r c$ synapses [area: light-adapted wild type, $0.02+/-0.006 \mu \mathrm{m}^{2}$ (SEM; $n=18$ ); light-adapted $n r c$, $0.23+/-0.03 \mu \mathrm{m}^{2}$ (SEM; $\left.n=20\right)$; perimeter: light-adapted wild type, $0.51+/-0.13 \mu \mathrm{m}$ (SEM; $n=18$ ), light-adapted $n r c, 5.76$ $+/-0.74 \mu \mathrm{m}$ (SEM; $n=20)]$. (Similar results were found for dark-adapted retinas.)

\section{Discussion}

In this study, we used the zebrafish nrc mutant to show that Synj1, a polyphosphoinositide phosphatase, is required for anchoring of 

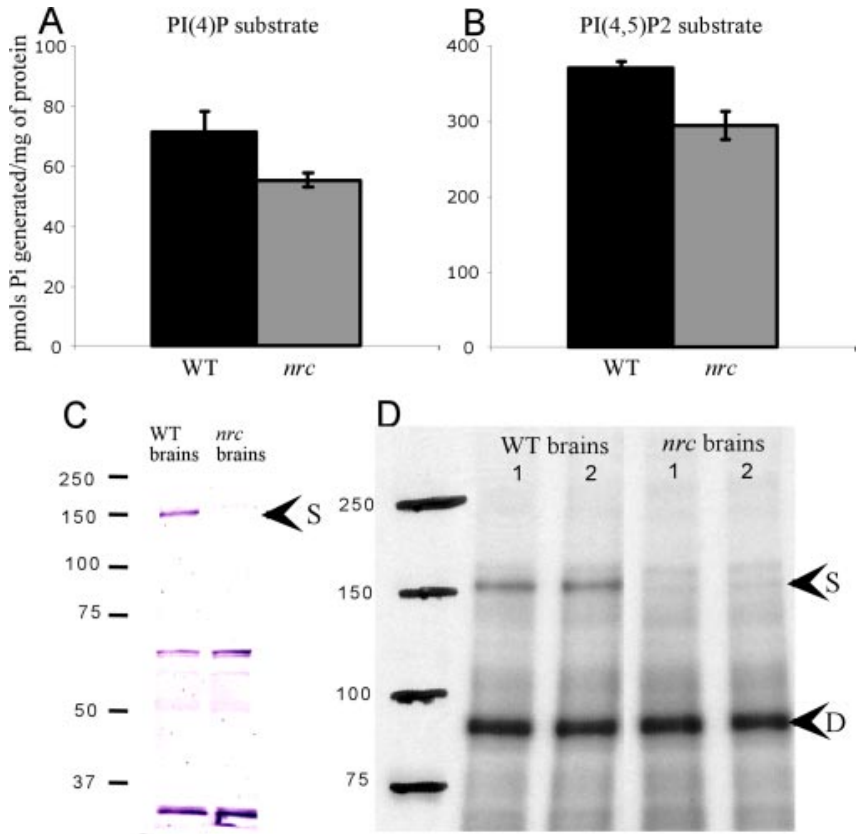

Figure 5. Phosphatase function and Synj 1 protein in $\operatorname{nrc}$ larvae. $A, B$, Free phosphate release from $\mathrm{PI}(4) \mathrm{P}$ and $\mathrm{PI}(4,5) \mathrm{P}_{2}$ substrates is reduced in extracts from nrc mutants. Free phosphategenerated per $\mathrm{mg}$ of cytosolic protein from $6 \mathrm{dpf}$ zebrafish larval extracts is plotted for WT and nrc mutants. $A, \mathrm{PI}(4) \mathrm{P}$ was used as substrate to test the activity of the Sacl phosphoinositide phosphatase domain. $B, P I(4,5) P_{2}$ was used as substrate to test the activity of the inositol 5 '-phosphatase domain. Error bars represent SDs. Standard two-tailed $t$ tests show that the differences between mutant and wild type are statistically significant $[P I(4) P, p=0.03$; $\left.\mathrm{PI}(4,5) \mathrm{P}_{2}, p=0.005\right]$. C, Immunoblotting of $6 \mathrm{dpf}$ zebrafish brain extracts reveals reduced levels of $\sim 150 \mathrm{kDa}$ Synj 1 (S) in nrc brain extracts. Five brains are loaded per lane. The $\sim 65$ and $\sim 30 \mathrm{kDa}$ proteins do not correspond to expected sizes of is forms or Sacl truncated products of synaptojanin and appear to be nonspecific. D, Endophilin overlay of larval zebrafish brain extracts. The $150 \mathrm{kDa}$ protein (Synj1) that binds to GST-endophilin is not present in $\operatorname{nrc} 6 \mathrm{dpf}$ larval brains. However, the GST-endophilin binding to the $\sim 95 \mathrm{kDa}$ protein (predicted size of dynamin) is observed in both WT and nrc brains from 6 dpf larvae. Lanes 1 and 2 are independent brain samples. Five brains are loaded per lane. S, Zebrafish Synj1; D, putative zebrafish dynamin with the expected electrophoretic mobility.

ribbons, for vesicle maintenance, and for synaptic transmission at cone photoreceptor ribbon synapses. We showed that the nrc mutation introduces a stop codon that truncates Synj1 just C terminal to its SacI phosphoinositide phosphatase domain. The zebrafish nrc mutant makes it possible to evaluate the role of Synj1 in the vertebrate retina. Previously, mice deficient in Synj1 have been characterized (Cremona et al., 1999; Di Paolo et al., 2002; Kim et al., 2002). However, the mutant mice die at postnatal day 1 , more than 1 week before ribbon synapses form and retinal function can be assessed. The abnormal swimming behavior of the zebrafish nrc mutant larvae suggests that the mutation causes multiple neurological defects, possibly including vestibular or lateral line defects. However, the larvae survive long enough for cone photoreceptor ribbon synapses to form and for synaptic transmission and vision to be evaluated by biochemical, morphological, and electrophysiological methods.

The protein encoded by the $n r c$ gene appears to be the zebrafish ortholog of mammalian Synj1. Zebrafish Synj1 has greater primary sequence similarity to mammalian Synj1 than to Synj2 (Fig. 1), and it cross-reacts with antibodies raised against rat Synj1 that do not recognize rat Synj2 (data not shown). In addition, conservation of critical protein-protein interaction sites between zebrafish Synj 1 and mammalian Synj1, as well as the binding of zebrafish Synj1 to rat endophilin, suggests functional
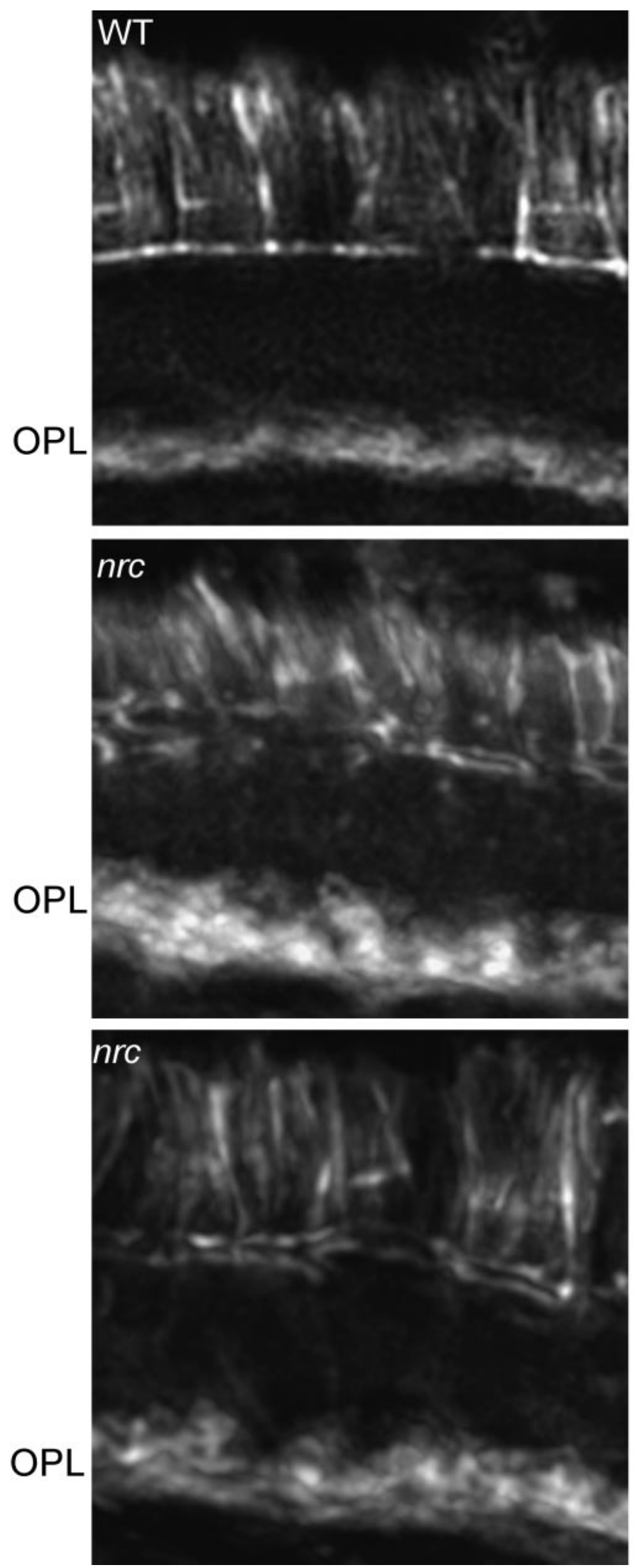

Figure 6. Actin localization. Fluorescence micrographs showing polymerized actin in the photoreceptor layer of $6 \mathrm{dpf}$ light-adapted $n r c$ retinas, as revealed by staining with phalloidin. The phalloidin staining is more uneven in $n r c$ than in wild type. Punctate regions of phalloidin staining are seen throughout the $\mathrm{nrc}$ OPL. No obvious differences in phalloidin staining were seen in the IPL (data not shown). All nrc larvae examined showed similar staining. 
conservation. The absence of a full-length Synj1 protein in $n r c$ was demonstrated by immunoblotting and GST-endophilin overlays. Furthermore, the decreased ability of $n r c$ whole larvae cytosol to dephosphorylate not only $\mathrm{PI}(4,5) \mathrm{P}_{2}$ but also $\mathrm{PI}(4) \mathrm{P}$ suggests that a truncated protein comprising the SacI domain alone is not present at a significant level and that the nrc mutation likely causes complete loss of Synj1 protein. This conclusion is further corroborated by the demonstration that a phenotype similar to that produced by the nrc mutation can be induced by morpholino-induced suppression of the expression of Synj1.

The main in vivo substrate of Synj at synapses is $\operatorname{PI}(4,5) \quad \mathrm{P}_{2}$, a plasma membrane-enriched phosphoinositide (Cremona et al., 1999). PI $(4,5) \mathrm{P}_{2}$ functions as a precursor of other signaling molecules such as DAG, $\mathrm{IP}_{3}$, and $\mathrm{PI}(3,4,5) \mathrm{P}_{3}$. In addition, $\mathrm{PI}(4,5) \mathrm{P}_{2}$ acts as a cofactor both in the nucleation of actin (Sakisaka et al., 1997; Cremona et al., 1999; Takenawa et al., 1999; Gad et al., 2000; Raucher et al., 2000; Takenawa and Itoh, 2001; Kim et al., 2002; Verstreken et al., 2003) and in the recruitment and assembly of clathrin coats and accessory factors (Cremona et al., 1999; Gad et al., 2000; Harris et al., 2000; Kim et al., 2002; Schuske et al., 2003). Abnormalities that occur in Synj-deficient synapses most likely reflect processes that are affected by impaired $\mathrm{PI}(4,5) \mathrm{P}_{2}$ hydrolysis leading to enhanced actin polymerization at endocytic/periactive zones and defects in shedding of clathrin coat components after endocytosis.

The predominant characteristics of Synj deficiency vary depending on the organism, the synapse, and the method (genetic disruption or antibody injection) used to disrupt Synj function. However, several structural characteristics of nrc mutant cone photoreceptor synapses resemble abnormalities that have been observed previously at conventional synapses of Synj-deficient nerve terminals in other organisms. These include peculiar rows of vesicles, like beads on a string (Harris et al., 2000; Schuske et al., 2003; Verstreken et al., 2003), the presence of a more pronounced cytoskeletal matrix than at normal nerve terminals (Cremona et al., 1999; Gad et al., 2000; Kim et al., 2002; Verstreken et al., 2003), and clusters of vesicles that often seem trapped in this matrix, isolated away from zones of secretion (Cremona et al., 1999; Gad et al., 2000; Allwardt et al., 2001; Kim et al., 2002; Verstreken et al., 2003). In other organisms, the membranes of these clustered vesicles are either more dense than the membranes of normal synaptic vesicles (Verstreken et al., 2003) or they are clathrin coated (Cremona et al., 1999; Gad et al., 2000; Harris et al., 2000; Kim et al., 2002; Schuske et al., 2003). The high density of the matrix in zebrafish synapses did not allow a clear visualization of clathrin coats, so a reliable morphometric analysis of coated structures could not be performed.

An additional defect shown by the present study is a decrease in the number of synaptic vesicles and an increase in endosomes within cone photoreceptor pedicles. This may reflect a disruption of the normal balance between exocytosis and endocytosis. Surprisingly, there were no obvious differences in the number of vesicles in cone synaptic terminals in dark- versus light-adapted retinas (data not shown). Photoreceptors continuously release neurotransmitter in the dark and decrease continuous release in the light. The similar reduction in the number of vesicles under both conditions suggests effects of Synj 1 deficiency on exocytosis and endocytosis that are similar at both low and high levels of activity.

Our study shows that ribbons in cone pedicles are unanchored at $6 \mathrm{dpf}$ in the absence of Synj. Rod spherules are not fully formed at this stage of development and could not be evaluated. In normal $6 \mathrm{dpf}$ retinas, $71 \%$ of cone photoreceptor ribbons are anchored, whereas in $n r c$ retinas only 14\% are anchored (Allwardt et al., 2001). Several mechanisms could contribute to this cone defect. As described in detail below, Synj1 may directly influence ribbon anchoring via phosphoinositide metabolism, or the role of Synj1 in endocytosis and actin rearrangement may indirectly influence ribbon anchoring.

1. The nrc photoreceptor synapse may be arrested or slowed in 
development (Allwardt et al., 2001). In teleost photoreceptor synapses, ribbons are first formed in the cytoplasm, then secondary neurons invaginate, and finally ribbons anchor to the plasma membrane. The development of the $n r c$ terminal may arrest before full invagination of secondary neurons and anchoring of ribbons can occur (Allwardt et al., 2001).

2. Critical rearrangements of the cytoskeleton may be compromised. Synj functions as a negative regulator of actin nucleation by dephosphorylating $\mathrm{PI}(4,5) \mathrm{P}_{2}$ (Singer-Kruger et al., 1998; Cremona et al., 1999; Takenawa et al., 1999; Gad et al., 2000; Harris et al., 2000; Stefan et al., 2002). Excess actin nucleation caused by the absence of Synj may cause ribbons to become abnormally tethered in the cytoplasm rather than at the plasma membrane. Excess $\mathrm{PI}(4,5) \mathrm{P}_{2}$ may alternatively cause misregulation of factors essential for the proper anchoring of the ribbon. Notably, phosphoinositides have been shown to influence ribbon anchoring at cone, but not rod, photoreceptors of carp retinas (Schmitz and Drenckhahn, 1993). Recent studies have demonstrated the presence of focal adhesion molecules at the ribbon synapse (Balkema et al., 2003). These proteins are regulated by $\mathrm{PI}(4,5) \mathrm{P}_{2}$ (Di Paolo et al., 2002; Ling et al., 2002; Calderwood and Ginsberg, 2003) and may be important in ribbon anchoring.

3. Synaptic function can influence ribbon anchoring. Precedence for this comes from other organisms. In mice lacking the $\beta 2$ subunit of the voltage-dependent L-type $\mathrm{Ca}^{+2}$ channel, photoreceptors can no longer signal properly, and ribbons become unanchored (Ball et al., 2002). When squirrels hibernate, ribbons detach from the membrane and then reattach after hibernation ends (Reme and Young, 1977). Finally, if an afferent nerve is cut, ribbons become unanchored. This has been observed in the ampulla of Lorenzini of the electrosensory organ of the fish Torpedo marmorata (Derbin, 1970).

Other synapses including bipolar cell ribbon synapses appear normal in $n r c$ mutants. This is surprising because Synj 1 is widely expressed in neurons. RNA whole-mount in situ hybridization revealed synj1 mRNA throughout the larval zebrafish brain. Furthermore, the nrc mutant displays abnormal balance and swimming, suggesting CNS neurological defects beyond blindness. It is unclear why cone photoreceptor pedicles are the most severely affected nerve terminals and why unanchored ribbons in other ribbon synapses are not increased in number. Unanchored ribbons occur in retinal photoreceptors in mice deficient in laminin $\beta 2$, the $\beta 2$ subunit of the L-type $\mathrm{Ca}^{+2}$ channel, and bassoon (Libby et al., 1999; Ball et al., 2002; Dick et al., 2003). However, a significant difference between these proteins and Synj1 is that laminin $\beta 2$ and bassoon are not present in bipolar ribbon synapses in the IPL. In contrast, Synj 1 is likely expressed in both photoreceptor and bipolar synapses.

It is possible that a second synj gene, not yet identified in the currently incomplete zebrafish genome database, may compensate for the loss of Synj1 at other synapses but not in photoreceptors. Alternatively, photoreceptor cells may have unique properties that make them inherently more susceptible to loss of Synj1 activity. This could include photoreceptor-specific regulation of other enzymes that control $\mathrm{PI}(4,5) \mathrm{P}_{2}$ metabolism or differences in the predominant pathways of synaptic vesicle recycling. For example, a recent study suggested that cone photoreceptors rely entirely on endocytosis of small vesicles (Rea et al., 2004), whereas endocytosis in bipolar cells is qualitatively different (Holt et al., 2003, 2004; Paillart et al., 2003). Interestingly, we found increased endosomes in nrc mutants. Furthermore, photoreceptors are more sensitive to defects in $\mathrm{Ca}^{2+}$ homeostasis, and the delay before the onset of endocytosis after the initial rise in $\mathrm{Ca}^{2+}$ is unusually short in photoreceptors (Rieke and Schwartz, 1996). Because the PI(4,5) $\mathrm{P}_{2}$ pools controlled by Synj are likely to be involved, at least indirectly, in $\mathrm{Ca}^{2+}$ signaling, Synj deficiency may have a more disruptive effect in photoreceptors because of a special mechanism of $\mathrm{Ca}^{2+}$ homeostasis in these cells. We note that mutations in synj were isolated in forward genetic screens for blindness both in Drosophila and in zebrafish. Phosphoinositide metabolism is critically implicated in the invertebrate phototransduction cascade but not in vertebrates (Yarfitz and Hurley, 1994). Studies of Drosophila (Verstreken et al., 2003) and zebrafish (Van Epps et al., 2001) photoreceptors have demonstrated a selective effect of Synj mutations on synaptic transmission and not on the phototransduction cascade. However, it is possible that important signaling functions of $\mathrm{PI}(4,5) \mathrm{P}_{2}$ at photoreceptor synapses have been conserved in evolution.

In conclusion, our analysis of the zebrafish $n r c$ mutant has demonstrated a special dependence of the cone photoreceptor ribbon synapse on the function of Synj. The $n r c$ mutant may now be used to further elucidate the general role of Synj in synaptic transmission and its special function at photoreceptors. In addition, it may help to reveal new aspects of the still elusive cell biology of ribbons.

\section{References}

Allwardt BA, Lall AB, Brockerhoff SE, Dowling JE (2001) Synapse formation is arrested in retinal photoreceptors of the zebrafish nrc mutant. J Neurosci 21:2330-2342.

Balkema G, Jones N, Chalifoux J, Mayer J (2003) Co-localization of focal adhesion proteins with the synaptic ribbon in the photoreceptor terminal. Soc Neurosci Abstr 29:475.13.

Ball SL, Powers PA, Shin HS, Morgans CW, Peachey NS, Gregg RG (2002) Role of the beta(2) subunit of voltage-dependent calcium channels in the retinal outer plexiform layer. Invest Ophthalmol Vis Sci 43:1595-1603.

Brockerhoff SE, Hurley JB, Janssen-Bienhold U, Neuhauss SC, Driever W, Dowling JE (1995) A behavioral screen for isolating zebrafish mutants with visual system defects. Proc Natl Acad Sci USA 92:10545-10549.

Brockerhoff SE, Hurley JB, Niemi GA, Dowling JE (1997) A new form of inherited red-blindness identified in zebrafish. J Neurosci 17:4236-4242.

Brockerhoff SE, Rieke F, Matthews HR, Taylor MR, Kennedy B, Ankoudinova I, Niemi GA, Tucker CL, Xiao M, Cilluffo MC, Fain GL, Hurley JB (2003) Light stimulates a transducin-independent increase of cytoplasmic $\mathrm{Ca}^{2+}$ and suppression of current in cones from the zebrafish mutant nof. J Neurosci 23:470-480.

Calderwood DA, Ginsberg MH (2003) Talin forges the links between integrins and actin. Nat Cell Biol 5:694-697.

Cestra G, Castagnoli L, Dente L, Minenkova O, Petrelli A, Migone N, Hoffmuller U, Schneider-Mergener J, Cesareni G (1999) The SH3 domains of endophilin and amphiphysin bind to the proline-rich region of synaptojanin 1 at distinct sites that display an unconventional binding specificity. J Biol Chem 274:32001-32007.

Chen Y, Deng L, Maeno-Hikichi Y, Lai M, Chang S, Chen G, Zhang JF (2003) Formation of an endophilin-Ca2 + channel complex is critical for clathrin-mediated synaptic vesicle endocytosis. Cell 115:37-48.

Corey DR, Abrams JM (2001) Morpholino antisense oligonucleotides: tools for investigating vertebrate development. Genome Biol 2:REVIEWS1015.1-1015.3.

Cremona O, Di Paolo G, Wenk MR, Luthi A, Kim WT, Takei K, Daniell L, Nemoto Y, Shears SB, Flavell RA, McCormick DA, De Camilli P (1999) Essential role of phosphoinositide metabolism in synaptic vesicle recycling. Cell 99:179-188.

De Camilli P, Cameron R, Greengard P (1983) Synapsin I (protein I), a nerve terminal-specific phosphoprotein. I. Its general distribution in synapses of the central and peripheral nervous system demonstrated by immunofluorescence in frozen and plastic sections. J Cell Biol 96:1337-1354.

Derbin C (1970) Effects de la section du nerve lateral sur les jonctions sensorineurales des ampuoules de Lorenzini de la Torpille Torpedo marmorata. J Microsc (Paris) 9:119-126.

Dick O, tom Dieck S, Altrock WD, Ammermuller J, Weiler R, Garner CC, Gundelfinger ED, Brandstatter JH (2003) The presynaptic active zone 
protein bassoon is essential for photoreceptor ribbon synapse formation in the retina. Neuron 37:775-786.

Di Paolo G, Pellegrini L, Letinic K, Cestra G, Zoncu R, Voronov S, Chang S, Guo J, Wenk MR, De Camilli P (2002) Recruitment and regulation of phosphatidylinositol phosphate kinase type 1 gamma by the FERM domain of talin. Nature 420:85-89.

Gad H, Ringstad N, Low P, Kjaerulff O, Gustafsson J, Wenk M, Di Paolo G, Nemoto Y, Crun J, Ellisman MH, De Camilli P, Shupliakov O, Brodin L (2000) Fission and uncoating of synaptic clathrin-coated vesicles are perturbed by disruption of interactions with the $\mathrm{SH} 3$ domain of endophilin. Neuron 27:301-312.

Guo S, Stolz LE, Lemrow SM, York JD (1999) SAC1-like domains of yeast SAC1, INP52, and INP53 and of human synaptojanin encode polyphosphoinositide phosphatases. J Biol Chem 274:12990-12995.

Ha SA, Torabinejad J, DeWald DB, Wenk MR, Lucast L, De Camilli P, Newitt RA, Aebersold R, Nothwehr SF (2003) The synaptojanin-like protein Inp53/Sjl3 functions with clathrin in a yeast TGN-to-endosome pathway distinct from the GGA protein-dependent pathway. Mol Biol Cell 14:1319-1333.

Haffner C, Di Paolo G, Rosenthal JA, de Camilli P (2000) Direct interaction of the $170 \mathrm{kDa}$ isoform of synaptojanin 1 with clathrin and with the clathrin adaptor AP-2. Curr Biol 10:471-474.

Harder KW, Owen P, Wong LK, Aebersold R, Clark-Lewis I, Jirik FR (1994) Characterization and kinetic analysis of the intracellular domain of human protein tyrosine phosphatase beta (HPTP beta) using synthetic phosphopeptides. Biochem J 298:395-401.

Harris TW, Hartwieg E, Horvitz HR, Jorgensen EM (2000) Mutations in synaptojanin disrupt synaptic vesicle recycling. J Cell Biol 150:589-600.

Holt M, Cooke A, Wu MM, Lagnado L (2003) Bulk membrane retrieval in the synaptic terminal of retinal bipolar cells. J Neurosci 23:1329-1339.

Holt M, Cooke A, Neef A, Lagnado L (2004) High mobility of vesicles supports continuous exocytosis at a ribbon synapse. Curr Biol 14:173-183.

Hukriede NA, Joly L, Tsang M, Miles J, Tellis P, Epstein JA, Barbazuk WB, Li FN, Paw B, Postlethwait JH, Hudson TJ, Zon LI, McPherson JD, Chevrette M, Dawid IB, Johnson SL, Ekker M (1999) Radiation hybrid mapping of the zebrafish genome. Proc Natl Acad Sci USA 96:9745-9750.

Kim WT, Chang S, Daniell L, Cremona O, Di Paolo G, De Camilli P (2002) Delayed reentry of recycling vesicles into the fusion-competent synaptic vesicle pool in synaptojanin 1 knockout mice. Proc Natl Acad Sci USA 99:17143-17148.

Ladman AJ (1958) The fine structure of the rod-bipolar cell synapse in the retina of the albino rat. J Biophys Biochem Cytol 4:459-466.

Lenzi D, Crum J, Ellisman MH, Roberts WM (2002) Depolarization redistributes synaptic membrane and creates a gradient of vesicles on the synaptic body at a ribbon synapse. Neuron 36:649-659.

Libby RT, Lavallee CR, Balkema GW, Brunken WJ, Hunter DD (1999) Disruption of laminin beta 2 chain production causes alterations in morphology and function in the CNS. J Neurosci 19:9399-9411.

Ling K, Doughman RL, Firestone AJ, Bunce MW, Anderson RA (2002) Type I gamma phosphatidylinositol phosphate kinase targets and regulates focal adhesions. Nature 420:89-93.

Luthi A, Di Paolo G, Cremona O, Daniell L, De Camilli P, McCormick DA (2001) Synaptojanin 1 contributes to maintaining the stability of GABAergic transmission in primary cultures of cortical neurons. J Neurosci 21:9101-9111.

McPherson PS, Garcia EP, Slepnev VI, David C, Zhang X, Grabs D, Sossin WS, Bauerfeind R, Nemoto Y, De Camilli P (1996) A presynaptic inositol-5-phosphatase. Nature 379:353-357.

Meng A, Jessen JR, Lin S (1999) Transgenesis. In: Methods in cell biology: the zebrafish: genetics and genomics (William H, Detrich I, Westerfield M, Zon LI, eds), pp 133-147. San Diego: Academic.

Nemoto Y, Wenk MR, Watanabe M, Daniell L, Murakami T, Ringstad N, Yamada H, Takei K, De Camilli P (2001) Identification and characterization of a synaptojanin 2 splice isoform predominantly expressed in nerve terminals. J Biol Chem 276:41133-41142.

Paillart C, Li J, Matthews G, Sterling P (2003) Endocytosis and vesicle recycling at a ribbon synapse. J Neurosci 23:4092-4099.
Parsons TD, Lenzi D, Almers W, Roberts WM (1994) Calcium-triggered exocytosis and endocytosis in an isolated presynaptic cell: capacitance measurements in saccular hair cells. Neuron 13:875-883.

Postlethwait JH, Johnson SL, Midson CN, Talbot WS, Gates M, Ballinger EW, Africa D, Andrews R, Carl T, Eisen JS, Horne S, Kimmel CB, Hutchinson M, Johnson M, Rodriguez A (1994) A genetic linkage map for the zebrafish. Science 264:699-703.

Raucher D, Stauffer T, Chen W, Shen K, Guo S, York JD, Sheetz MP, Meyer T (2000) Phosphatidylinositol 4,5-bisphosphate functions as a second messenger that regulates cytoskeleton-plasma membrane adhesion. Cell 100:221-228

Rea R, Li J, Dharia A, Levitan ES, Sterling P, Kramer RH (2004) Streamlined synaptic vesicle cycle in cone photoreceptor terminals. Neuron 41:755-766.

Reme CE, Young RW (1977) The effects of hibernation on cone visual cells in the ground squirrel. Invest Ophthalmol Vis Sci 16:815-840.

Rieke F, Schwartz EA (1996) Asynchronous transmitter release: control of exocytosis and endocytosis at the salamander rod synapse. J Physiol (Lond) 493:1-8.

Ringstad N, Nemoto Y, De Camilli P (1997) The SH3p4/Sh3p8/SH3p13 protein family: binding partners for synaptojanin and dynamin via a Grb2-like Src homology 3 domain. Proc Natl Acad Sci USA 94:8569-8574.

Ringstad N, Gad H, Low P, Di Paolo G, Brodin L, Shupliakov O, De Camilli P (1999) Endophilin/SH3p4 is required for the transition from early to late stages in clathrin-mediated synaptic vesicle endocytosis. Neuron 24:143-154.

Ringstad N, Nemoto Y, De Camilli P (2001) Differential expression of endophilin 1 and 2 dimers at central nervous system synapses. J Biol Chem 276:40424-40430.

Sakisaka T, Itoh T, Miura K, Takenawa T (1997) Phosphatidylinositol 4,5bisphosphate phosphatase regulates the rearrangement of actin filaments. Mol Cell Biol 17:3841-3849.

Schmitz F, Drenckhahn D (1993) Li(+)-induced structural changes of synaptic ribbons are related to the phosphoinositide metabolism in photoreceptor synapses. Brain Res 604:142-148.

Schuske KR, Richmond JE, Matthies DS, Davis WS, Runz S, Rube DA, van der Bliek AM, Jorgensen EM (2003) Endophilin is required for synaptic vesicle endocytosis by localizing synaptojanin. Neuron 40:749-762.

Shimoda N, Knapik EW, Ziniti J, Sim C, Yamada E, Kaplan S, Jackson D, de Sauvage F, Jacob H, Fishman MC (1999) Zebrafish genetic map with 2000 microsatellite markers. Genomics 58:219-232.

Singer-Kruger B, Nemoto Y, Daniell L, Ferro-Novick S, De Camilli P (1998) Synaptojanin family members are implicated in endocytic membrane traffic in yeast. J Cell Sci 111:3347-3356.

Stefan CJ, Audhya A, Emr SD (2002) The yeast synaptojanin-like proteins control the cellular distribution of phosphatidylinositol (4,5)bisphosphate. Mol Biol Cell 13:542-557.

Takenawa T, Itoh T (2001) Phosphoinositides, key molecules for regulation of actin cytoskeletal organization and membrane traffic from the plasma membrane. Biochim Biophys Acta 1533:190-206.

Takenawa T, Itoh T, Fukami K (1999) Regulation of phosphatidylinositol 4,5-bisphosphate levels and its roles in cytoskeletal re-organization and malignant transformation. Chem Phys Lipids 98:13-22.

Van Epps HA, Yim CM, Hurley JB, Brockerhoff SE (2001) Investigations of photoreceptor synaptic transmission and light adaptation in the zebrafish visual mutant nrc. Invest Ophthalmol Vis Sci 42:868-874.

Verstreken P, Koh TW, Schulze KL, Zhai RG, Hiesinger PR, Zhou Y, Mehta SQ, Cao Y, Roos J, Bellen HJ (2003) Synaptojanin is recruited by endophilin to promote synaptic vesicle uncoating. Neuron 40:733-748.

von Gersdorff H, Vardi E, Matthews G, Sterling P (1996) Evidence that vesicles on the synaptic ribbon of retinal bipolar neurons can be rapidly released. Neuron 16:1221-1227.

Westerfield M (1994) The zebrafish book: a guide for laboratory use of zebrafish (Brachydanio rerio), Ed 2.1. Eugene, OR: University of Oregon.

Yarfitz S, Hurley JB (1994) Transduction mechanisms of vertebrate and invertebrate photoreceptors. J Biol Chem 269:14329-14332. 